\title{
Bridging the gap between observational oceanography and users
}

\author{
Christiane A. Eschenbach \\ Institute of Coastal Research, Helmholtz-Zentrum Geesthacht, Centre for Materials and \\ Coastal Research, 21502 Geesthacht, Germany
}

Correspondence to: Christiane A. Eschenbach (christiane.eschenbach@hzg.de)

Received: 29 April 2016 - Discussion started: 14 June 2016

Revised: 11 November 2016 - Accepted: 16 November 2016 - Published: 23 February 2017

\begin{abstract}
In order to ensure relevance and societal impact of research and to meet the various requirements of different target groups, the Coastal Observing System for Northern and Arctic Seas (COSYNA) developed and pursued a broad range of activities for knowledge transfer and stakeholder interaction. Potential user groups of data and data products include (but are not limited to) science, administration, renewable energies, engineering, tourism, and nature conservation. COSYNA data and data products are publicly accessible and available free of charge via the Internet (data portal; www.cosyna.de).

The stakeholder interaction is integrated into the COSYNA product life cycle outlined here and the steps undertaken are exemplified for the product "Surface Current Fields in the German Bight". Initial surveys revealed COSYNA's potential relevance in the national and international context. After the technological and mathematical realization of high-quality parameter fields, external experts evaluated the scientific value, informational value, innovative leap, cost/benefit aspects, operability, etc., of the data products. In order to improve products and their usability and to pave the way for future co-operation, interviews and workshops with potential users from the offshore wind energy industry were conducted. The stakeholder interaction process was successful, revealing relevant insights into user demands and usability of (possible) products. Analysis of data download provided some evidence for impact beyond academia. Other criteria for the increasingly demanded evaluation of the impact of coastal research are discussed. By sharing first-hand experiences, this study contributes to the emerging knowledge on integration of science and end users.
\end{abstract}

\section{Introduction}

Integrating stakeholder perspectives from outside academia is of increasing importance in ocean and coastal science. The role of science in society has changed considerably during recent decades. Scientists are increasingly asked to consider the salience of their work in relation to the needs of the public and its legitimacy among stakeholders beyond their scientific peers (e.g. Cash et al., 2003; Welp et al., 2006; Allen et al., 2013; von Storch et al., 2015). Knowledge on transdisciplinary approaches is considered to benefit from project experiences (Jahn et al., 2012; Bergmann et al., 2016) and "more guidance grounded in actual project experiences is needed" (DeLorme et al., 2016). Thus, the purpose of this study is to convey first-hand experiences on stakeholder interaction and transdisciplinary orientations from the Coastal Observing System for Northern and Arctic Seas (COSYNA).

COSYNA was established in the German North Sea and off the coast of Spitsbergen to describe, analyse, and predict the environmental status of coastal waters. Combining observations, numerical modelling, data management, and outreach activities, the system provides data and knowledge tools to help science, public administration, industry, and the public make informed decisions (see also Baschek et al., 2016).

The COSYNA mission meets the societal requirements for sustainable future developments of marine and coastal regions as set forth, for example, by the Marine Strategy Framework Directive (MSFD; directive 2008/56/EC) and the Copernicus Marine Environment Monitoring Service, the latter striving to implement services coupled with efficient downstream processing to support marine applications. Using this approach, observation methodologies developed in COSYNA support monitoring strategies and can contribute 


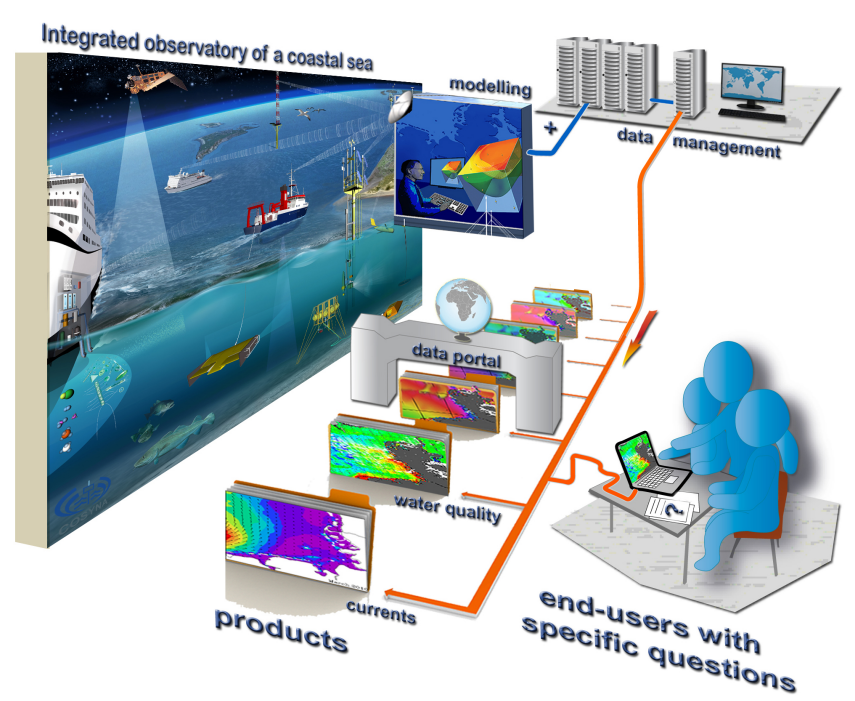

Figure 1. The integrated COSYNA approach: combination of observations and numerical modelling, data management, and stakeholder interactions (COSYNA presentation; www.cosyna.de).

to "Good Environmental Status" and sustainable development of the North Sea. Because the North Sea is one of the most heavily used coastal areas in the world, lessons learned in this region may serve as a role model for similar challenges and interactions in other coastal regions worldwide.

In order to ensure relevance and societal impact and to meet the various requirements of different target groups, a broad range of activities for knowledge transfer and stakeholder interaction was developed and pursued. Stakeholder feedback was and is necessary to further improve the COSYNA products.

While currently considerable expertise has been developed in delivering services in other fields of natural science, such as in climate services (McNie, 2013; Vaughan and Dessai, 2014; Bowyer et al., 2015), marine and coastal products and services are still in their infancy (e.g. Kourafalou et al., 2015a; von Storch et al., 2015). Societal benefits of coastal ocean observing systems have, for example, been demonstrated in the USA to support marine safety, water quality, and effective coastal management decision-making (Buskey et al., 2015; Porter et al., 2015; Simoniello et al., 2015). In Europe, the Marine Strategy Framework Directive provides the background for supporting the need for stronger and more effective oceanographic research interaction with the diverse (often conflicting) interest groups, using various marine or coastal resources. With regard to the marine area, collaborative research is most common in fisheries (e.g. Mackinson et al., 2010). However, in the coastal area, we can still observe a mismatch between knowledge production in academia and knowledge requests for solving societal problems (HoffmanRiem et al., 2008; Diedrich et al., 2010; Kourafalou et al., 2015b).
In order to overcome this mismatch, products and services concerning the state of the North Sea were developed for various users of oceanographic data and forecasts (Fig. 1). COSYNA products range from time series at various locations and regular maps of parameters, such as currents, waves, salinity, temperature, chlorophyll, or oxygen, to routine short-term forecasts (days) for these parameters.

Potential users include (but are not limited to) those from the fields science, administration, renewable energies, tourism, and nature conservation. For example, the Federal Maritime and Hydrographic Agency (Bundesamt für Seeschifffahrt und Hydrographie, BSH) measures and calculates sea surface temperatures, waves, currents as well as current and wave predictions from their operational observation and model systems and make them available to the various users and the public. An improvement of these services is considered through further development of COSYNA measurements and products.

This study, in particular, focuses on interest groups from the offshore wind energy sector. Offshore wind energy farms are a recent addition to human utilization in the North Sea, an area with strong offshore wind potential in Europe. In the context of global climate change and in order to reduce $\mathrm{CO}_{2}$ emissions resulting from human activities, the number and size of offshore wind energy farms have significantly increased in recent years. Germany's offshore wind farms generated $1.3 \%$ of the overall energy produced nationwide in 2015 , a $550 \%$ increase compared to a $0.2 \%$ contribution by offshore wind turbines in 2014 (http://www.offshorewind. biz/2015/12/21/; according to data from the German Association of Energy and Water Industries). Currently there are approximately 36 offshore wind farm projects either in operation (12), under construction (5), or licensed (19) in the German North Sea (http://www.wab.net/images/stories/ Offshore_Wind_Farms_in_the_German_North_Sea.pdf). As offshore wind energy is rapidly proliferating in Germany and Europe (Deutscher Bundestag, 2000; Commission of the European Communities, 2007; Pineda, 2015), and this development points to a global trend, businesses and other stakeholders from the wind energy sector are important (potential) users of oceanographic data and forecasts. The new and intensified use of wind energy brings benefits and new challenges. The latter includes coping with harsh environmental conditions in the North Sea and ensuring safe, but efficient and effective maintenance and operation of the wind farms, while at the same time minimizing the environmental impact. The potential influence of offshore wind farms on North Sea ecosystems and the aim of preserving fragile ambient ecosystems is not the subject of this study (see, e.g., Bailey et al., 2014; Clark et al., 2014).

In general terms, transdisciplinary approaches mean that researchers from different academic disciplines work together with stakeholders. Different intensities of interaction between science and stakeholders can be differentiated; information, consultation, co-operation, collaboration, and em- 


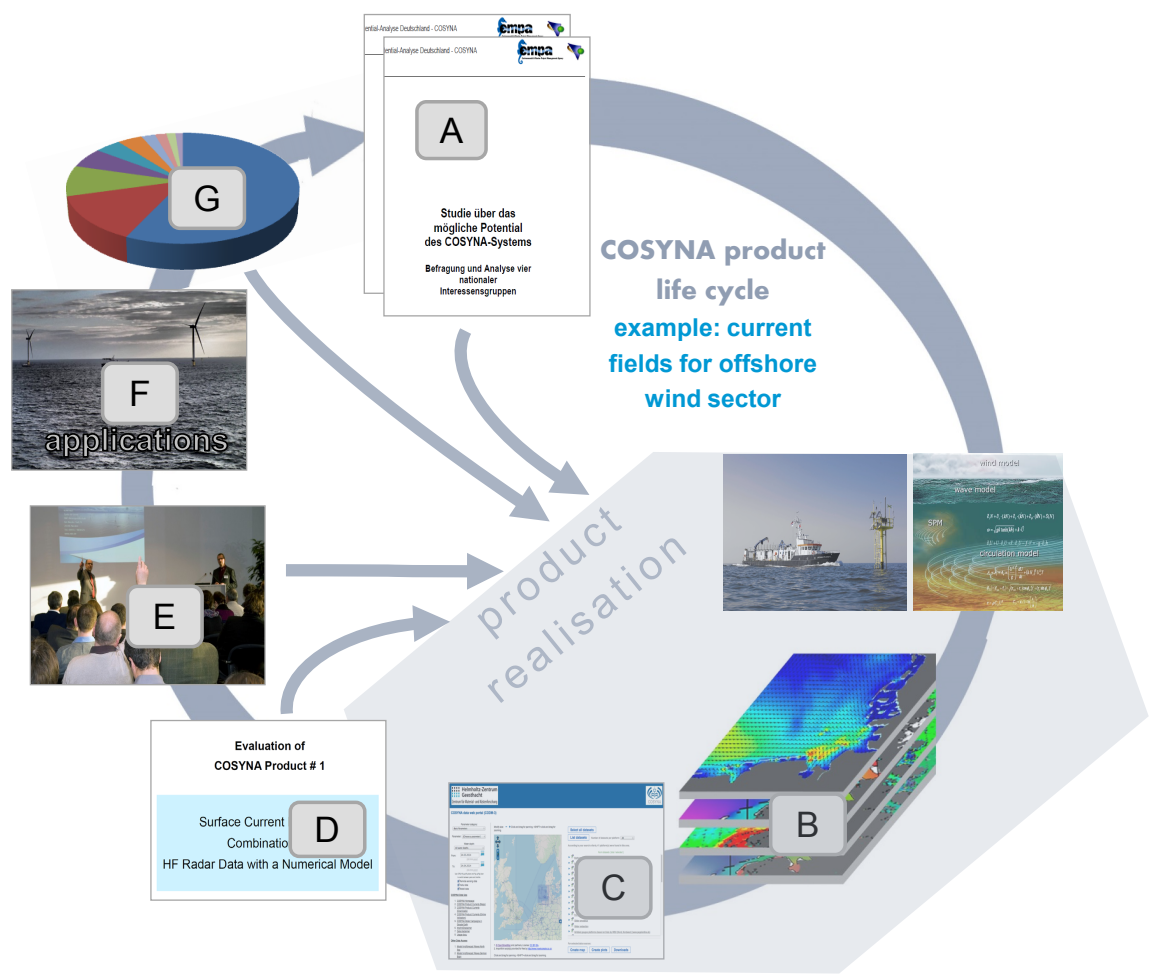

Figure 2. COSYNA product life cycle depicted for the COSYNA product "Surface Current Fields in the German Bight" as an example: (a) initial surveys reveal COSYNA's potential relevance, (b) the technological and mathematical realization provides optimized parameter fields for currents, waves, temperature, etc., (c) the data are freely accessible via the COSYNA data portal, (d) external evaluation of COSYNA products, (e) interviews and workshops with stakeholders from the offshore wind sector, (f) improved COSYNA products are available to users, $(\mathbf{g})$ evaluation of impact.

powerment form a sequence from low to high intensity in transdisciplinary approaches (Brinkmann et al., 2015; Stauffacher et al., 2008; Wiek, 2007). There are numerous definitions for transdisciplinarity in literature, but a generally accepted definition is still not available. Generally agreed upon main features are addressing a real-world problem, integrating different disciplines, and involvement of non-academic stakeholders (Bergmann et al., 2016; DeLorme et al., 2016; Jahn et al., 2012; Hirsch Hadorn et al., 2008). Transdisciplinarity combines interdisciplinarity (collaboration between researchers from different disciplines aimed at a synthesis and integration of knowledge; Bernstein, 2015) and interactions with extra-academic interest groups, for example from industry, governments, and non-governmental organizations. Little experience in transdisciplinary approaches exists in coastal research. Marine or coastal topics are, for example, lacking in the Handbook of Transdisciplinary Research (Hirsch Hadorn et al., 2008). However, some overlapping of transdisciplinarity and the current flourishing field of citizen science exists, as both are dealing with participation of nonscientists or non-academic scientists. In recent years, thousands of volunteers ("citizen scientists") have participated in marine research activities (Thiel et al., 2014). Citizen science can support integration in transdisciplinary endeavours (Pettibone and Lux, 2015).

In terms of stakeholder interactions, it is helpful to distinguish between the product (e.g. data products or new technologies, concerning the "what?") and the process (dealing with the "how?"). While this study tackles both these components, it focuses, however, on the process. For improving the process, it is essential to answer the question of whether stakeholder interactions did in fact work and achieve their goals. Agreed upon processes for collaboration, in particular in the field of coastal ocean observing systems, are still fragmentary (e.g. Liu et al., 2015; DeLorme et al., 2016). Quality standards and evaluation criteria for transdisciplinary processes are widely lacking (e.g. Jahn et al., 2012). As evaluation criteria for the impact of (successful) stakeholder interactions are absolutely essential, they are a matter of active discussion. Outcomes of this study are expected to support criteria development and contribute to the ongoing discussion.

Thus, the focus of the study is 3 -fold: 
- to improve the COSYNA products by stakeholder interaction;

- to share a practice example on transdisciplinary orientations in coastal research;

- to contribute to criteria development for impact evaluation.

\section{The COSYNA product life cycle}

In order to identify and depict those phases of the COSYNA product development procedure that are the most relevant for stakeholder interaction, an iterative multi-step cycle was developed. The conceptual framework is based on two approaches used in business:

1. According to the product life concept (usually referred to as a life cycle, e.g. Rebitzer et al., 2004) every product has a "life", starting with design and development, followed by production, provision and use, and endof-life activities. The development of a pre-operational integrated COSYNA product comprises different aspects and can be depicted as the "COSYNA product life cycle" (Fig. 2): while the product realization (B, C) is mainly a technological and mathematical challenge, development of the product idea (A), product evaluation (D), interviews, workshops (E), and impact evaluation $(\mathrm{G})$ require stakeholder interaction. Effort at these phases of the product life cycle is required to initiate and maintain a two-way information flow, where potential users and external evaluators provide feedback. The product application $(\mathrm{F})$ in political or management decisions by authorities, enterprises, and other users is subject to other driving forces and not part of COSYNA. In order to improve the products and to ensure they are useful and applicable, interaction with (potential) users was established step-by-step.

2. The iterative management method PDCA (plan-docheck-act or plan-do-check-adjust) is a tool to incorporate feedback and to break down the development, implementation, and continuous improvement of processes or products into small manageable steps. When applied to the life cycle of coastal scientific products, such as COSYNA products, stakeholder interaction would ideally be assessed in the following way. The first step would be to identify possible stakeholders by means of a stakeholder mapping exercise. During the initial phase of problem definition, consensus should be reached on the research question and the objectives of the project by all parties concerned, for example through a series of stakeholder workshops. It is considered essential that scientists and practitioners contribute their specific knowledge and speak to each other as equals. After common understanding is achieved during the "planning" phase, potential solutions should be generated and tested on a small scale ("do" phase). For an initiative such as COSYNA, this means starting with the development of one typical product. Thus, measuring and modelling concepts and devices are developed and established, and a parameter field, for example current fields in the German Bight, is provided at a preoperational level. During the "check" phase, potential users would be asked for evaluation of and feedback on the pre-operational product. Assessment data should be gathered on a statistically sound basis with potential users from different groups. However, lack of resources often constrains the ideal number of stakeholders involved and the activities that can be carried out. The results of structured quantitative and qualitative analyses should be fed back into the development cycle, meaning that aspects mentioned by potential users should really influence further product development. The "do" and "check" phases could be repeated several times to polish the product and its usability until all the stakeholders agree on the usefulness of the final product. Finally, the improved solution is fully implemented ("act"). Any evaluation of products and stakeholder processes requires success criteria and indicators that need to be set in advance, ideally with stakeholders.

In practice, the steps depicted in Fig. 2 and described in detail in the following sections were performed during the development of an integrated pre-operational COSYNA product.

\section{The steps of the "COSYNA product life cycle" in practice}

The COSYNA stakeholder interaction concept follows a structured process encompassing a broad range of different interaction activities. The stakeholder interaction process continued as the initiative progressed and developed further with the development of the products. As is well known for projects, interactions in the beginning had more influence on the design of the whole COSYNA initiative than later steps. During the initial phases, data demands related to, e.g., parameters, accuracy, data resolution, and the design of measurements and approaches were of greater focus. During later stages, feedback of (potential) users on the pre-operational products, data presentation in the data portal, and the user interface played a more important role. Later, during the implementation phase, interaction activities concentrated on fine tuning and improving the usability of the products.

During the course of the project, the range of stakeholders changed; i.e. the range of interest groups addressed was broad in the beginning and later increasingly focused on key stakeholders. However, all the interest groups involved during the different phases contributed their specific practitioners' experiences, and their specific demands regarding 
oceanographic data products, concerning parameters, types, resolution, etc. Thus, real-world questions were taken into account in the design of the COSYNA initiative.

\subsection{Initial surveys (A)}

\subsubsection{International dimension}

A feasibility study on COSYNA's international dimension (Laane, 2010; HZG internal report) was conducted with special attention to the planned networking activities and to assess the international scientific contacts and connections with networks, organizations, and projects. The study stated that "coastal observatories are nowadays the backbone for scientific exploration, operational information and management of coastal ecosystems" and that COSYNA fits very well within the worldwide development of coastal observatories. According to the study, the COSYNA strategy to improve and streamline access to high-quality marine data should be completed with tailor-made communication plans for communicating to the various end users. The study concludes that COSYNA's goal, to collect information and data to understand the short and long-term dynamics in coastal ecosystems, fulfils the need of international EU directives, conventions, and agreements.

Information on user requirements at a European level was also available from the "Operational Oceanography: Data Requirements Survey" (sample from 155 organizations in six countries; Fischer and Flemming, 1999) conducted by the association of European national agencies for developing operational oceanographic systems and services in European seas (European Global Ocean Observing System, EuroGOOS). COSYNA products were to cover these requirements to a large extent. This applies to the parameters measured (e.g. current, waves, sea surface temperature, salinity, wind, bathymetry, sediment, and some biogeochemical parameters), the geographical coverage (coastal and shelf areas), the spatial (and temporal) resolution, and the product types, such as processed data, hindcasts, and forecasts.

\subsubsection{Requirements of potential national and regional user groups}

During COSYNA's early stages, a second survey provided information on the specific demands and requirements of potential national and regional user groups in the northern German coastal area (Ahrendt and Wesnigk, 2009; HZG internal report). The initial survey addressed a broad range of organizations including science (universities and other research institutions), federal and state authorities, public administration, tourism, nature conservation, international and regional NGOs, private enterprises, fishermen, consulting groups, engineering companies, etc. The interviewees were categorized to represent four interest groups, namely (number of responses in parenthesis) authorities (10); nature conserva- tion, tourism, and other NGOs (10); science (universities and other research institutions, 18); and businesses (with focus on offshore wind energy, 21). A majority of the interviewees $(71 \%)$ use external data from other organizations with a preference for processed $(30 \%)$ and cleansed data $(31 \%)$ over raw data. The study identified meteorological data, currents, waves, bathymetry, turbidity, and water temperature as the most useful parameters to potential national and regional users. Data on salinity, nutrients, oxygen, chlorophyll, and higher trophic levels (marine mammals, fish, birds) were also often in demand. Forecasts and simulations $(81 \%)$, oceanographic modelling data $(76 \%)$, meteorological modelling data, reconstructions of storm surges, waves, water level, and mathematical modelling of habitats were in high demand (for more details see Eschenbach, 2013). Thus, the COSYNA approach combining measurements and modelling was designed to meet these requirements. In accordance with the outcomes of the survey, the first COSYNA products to be realized were maps and forecasts of surface current fields in the German Bight. Data products on waves, temperature, and salinity were next in COSYNA's portfolio.

\subsection{The technological and mathematical realization provides optimized parameter fields (B)}

The COSYNA product "Surface Current Fields in the German Bight" may serve as an example (for details on measurements, modelling, and data assimilation; see SchulzStellenfleth et al., 2010; Stanev et al., 2011, 2015). The product "Surface Current Fields in the German Bight" is the first pre-operational analysis system for surface currents based on real-time high frequency (HF) radar data. Currents are provided in real time, for the last $18 \mathrm{~h}$ and as a $6 \mathrm{~h}$ forecast. The maps and forecasts are updated hourly. The resolution in the area of the German Bight is $1 \mathrm{~km}$ and the product deviation from the measured HF-radar current data is typically about $0.1 \mathrm{~m} \mathrm{~s}^{-1}$, with large regional deviations

\subsection{The data are made freely accessible via the COSYNA data portal $(\mathrm{C})$}

The COSYNA data portal (codm.hzg.de; see also www. cosyna.de) presents all COSYNA data and metadata comprehensively, free of charge and is made available to everyone. The data portal serves as the user interface for data retrieval and presentation and aims at multi-purpose data use. The user can select parameter, data sources, time range, and presentation type (overlay raster map or time-series diagram) and can download the selected data. Thus, for example, maps of current fields can be inspected and time series of current maps (in netCDF format) are publicly available for download. For details about the numerous distinctive features of the COSYNA data portal, see Breitbach et al. (2016). 


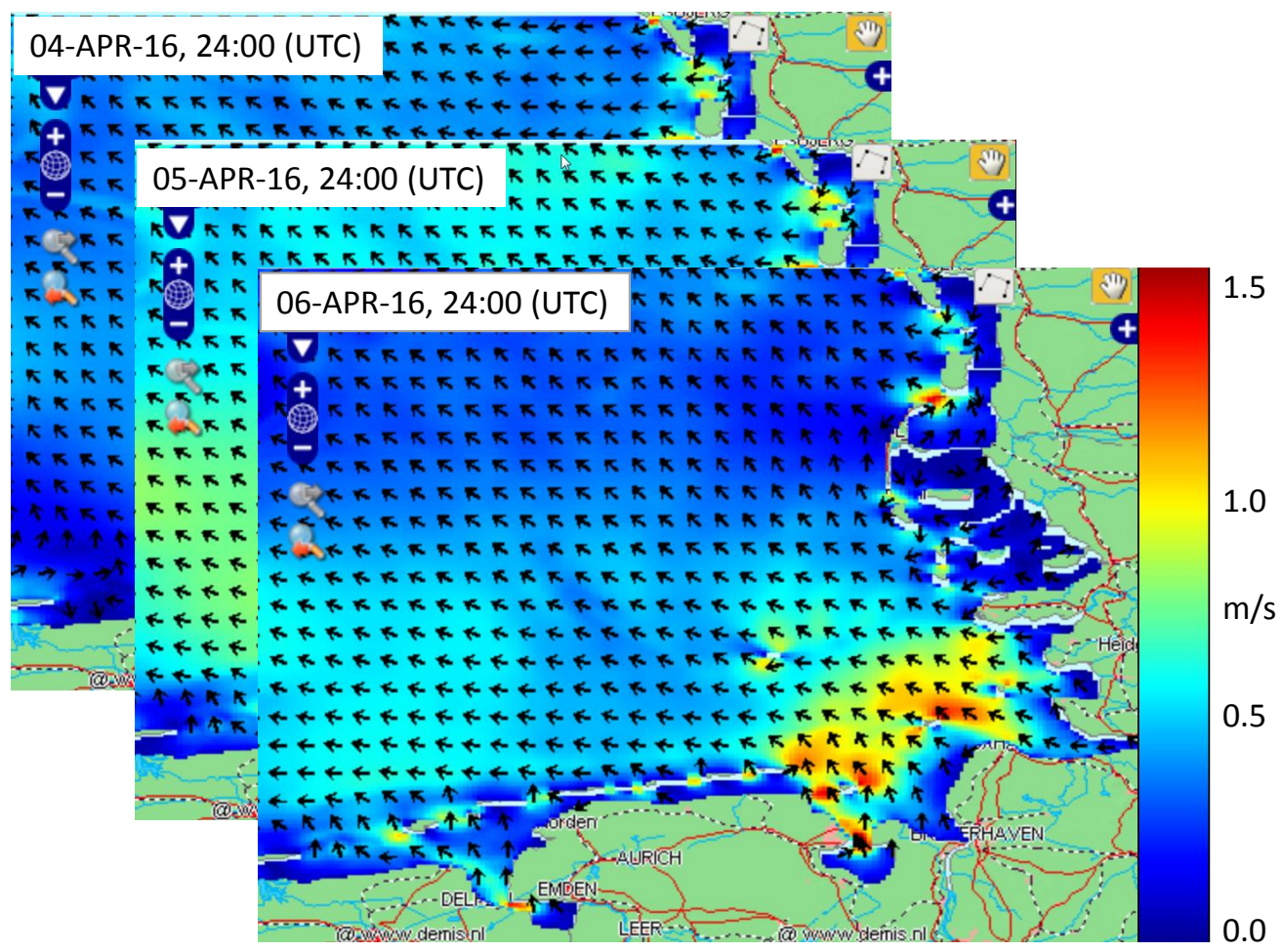

Figure 3. COSYNA product "Surface Current Fields in the German Bight" (snapshot 4-6 April 2016, COSYNA data portal, based on the algorithm described in Stanev et al., 2015).

\subsection{External evaluation of COSYNA products (D)}

After realization but before implementation of the first product, "Pre-operational Surface Current Fields", and during detailed planning of the second product, "Temperature and Salinity", a group of national and international evaluators were asked for their expert opinion on the COSYNA products. The evaluators were selected according to the outcomes of the initial surveys. These showed that NGOs or fishermen were less interested in oceanographic data, such as currents and waves, but that scientists were a priority user group. Therefore, four evaluators were chosen, representing the user groups of administration, private enterprise, and science. The two science representatives substantially differ in their fields of interest: (1) numerical ocean models and data assimilation, and (2) coastal observation with the aim of understanding the system and the influences of forcing factors.

The evaluators were asked to fill a multiple choice questionnaire, to provide detailed written statements, and to present and discuss their results during a 1-day workshop. The criteria for the evaluation were scientific value, informational value (as compared with other existing informational sources), innovative leap, potential users and target groups, cost/benefit aspects, operating reliability/availability, and user interface/operability of the COSYNA products, in particular of the current product.
The evaluators identified the scientific-technical value as high and the informational value and innovative leap as above average, and they saw proper potential applications and usages. They recommended, however, improvement of the user interface (Table 1). Consequently, efforts were made to achieve more user-friendly data presentations and download possibilities. New features increased the usability of the data portal (see Sect. 3.3, and Breitbach et al., 2016).

\subsection{Interviews and workshops with stakeholders: case study “offshore wind energy" (E)}

During implementation, COSYNA interacted with different interest groups in order to support the applicability and usability of its products. This study, in particular, focuses on interest groups from the offshore wind energy sector. Planning, construction, and operation of offshore wind farms as well as maintenance procedures under difficult weather and oceanographic conditions in the North Sea might considerably profit from COSYNA products on currents and waves. The offshore wind energy sector is multi-disciplinary and heterogeneous in itself, including specialists of very different fields, such as energy companies, insurance companies, specialists for installation ships or offshore converters, consultants, or divers. As the interaction with stakeholders from the offshore wind sector may serve as a case study, it is de- 
Table 1. Evaluator feedback on the product "Pre-operational Surface Current Fields" (values from 1: bad/low to 5: good/high).

\begin{tabular}{lrrrr}
\hline & Administration & $\begin{array}{r}\text { Private } \\
\text { enterprises }\end{array}$ & Science1 & Science2 \\
& 5 & 5 & 3 & 5 \\
\hline Scientific-technical value & 4 & 4 & 4 & 4 \\
Information & 4 & 4 & 3 & 5 \\
Innovation & 3 & 4 & 4 & - \\
Cost/benefit & 4 & 4 & 3 & 4 \\
Operating reliability & 3 & 3 & 4 & - \\
User interface & 4 & 3 & 4 & - \\
Match user needs & & & & \\
\hline
\end{tabular}

scribed in detail in the following. The focus is on interviews and workshops.

Jointly and in co-operation with the BSH and the German Weather Service (DWD), we contacted offshore wind energy organizations, such as operators, consultants, insurance companies, and others, aiming at a two-way information flow, co-operation, or collaboration. The purpose of the interaction with stakeholders from the offshore wind energy sector from our point of view was 3-fold: (1) first, to improve existing COSYNA products through interaction with potential users, to demonstrate their applicability for real-life situations, and to gather further information on products to be developed (e.g. information on parameters, spatial and temporal resolution, and accuracy). (2) Second, we proposed to exchange existing data with wind farm operators for mutual benefit. (3) The third idea was to possibly take measurements within wind farms and use these measurements to obtain data that are otherwise rarely available to science.

As the wind energy industries could likewise benefit from our measurements, models, and improved analysis and prognosis tools as well as from obtaining weather and oceanographic data free of cost, we expected to generate a win-win situation.

The following major efforts were undertaken to establish and maintain interactions with potential COSYNA product users from the offshore wind energy sector:

- participation in offshore wind exhibitions and public events to make contacts;

- first series of interviews in order to prepare for the first workshop;

- realization of a user workshop with approximately 100 participants;

- evaluation of the workshop outcomes and postprocessing (wrap up);

- second series of interviews in order to prepare for the second, more topic-oriented workshop;

- realization of the second workshop with a limited number of participants and focusing on currents and waves;
- meetings with representatives of offshore wind energy companies to arrange concrete collaborations;

- evaluation of the outcomes of the interaction efforts.

The listed efforts were undertaken jointly and in very fruitful co-operation with the BSH and the DWD. In the following, I focus on the interviews and workshops.

\subsubsection{Interviews}

Through personal contacts, literature, and internet research, potential interested parties from the offshore wind energy industrial sector were identified. The first series of interviews was conducted with representatives of nine companies from the construction, operation and maintenance, and consulting fields. The second series comprised seven interviews with selected participants of the first workshop. All the interviews were guideline based and in-depth. In preparation of the actual interviews a set of potential guiding questions was identified. During the interviews, the initial and guiding questions were tailored according to the interviewees. Their answers in large parts shaped subsequent questions. The interviews were conducted face-to-face or (a few) via phone, and all of them took approximately $1 \mathrm{~h}$ or more. The information gathered during the interviews was compiled and analysed. The general interviewing process followed the steps identified by Kvale (1994).

Concerning data use and requirements, major results of the first series of interviews showed that most enterprises use two or more weather forecasts, including oceanographic data, and would be interested in additional high-quality and freely available data. Most business enterprises working in the offshore wind sector have their own measurement equipment in situ. This is especially true for those who employ workers, such as divers, who vitally depend on these measurements.

Data use and requirements of the different companies span a wide range, from raw to processed and evaluated data in various formats, which should be provided through a variety of user interfaces. Forecasts for several hours were mentioned as most welcome. Forecasts of extreme events, e.g. storm surges, were also requested. In general, consis- 


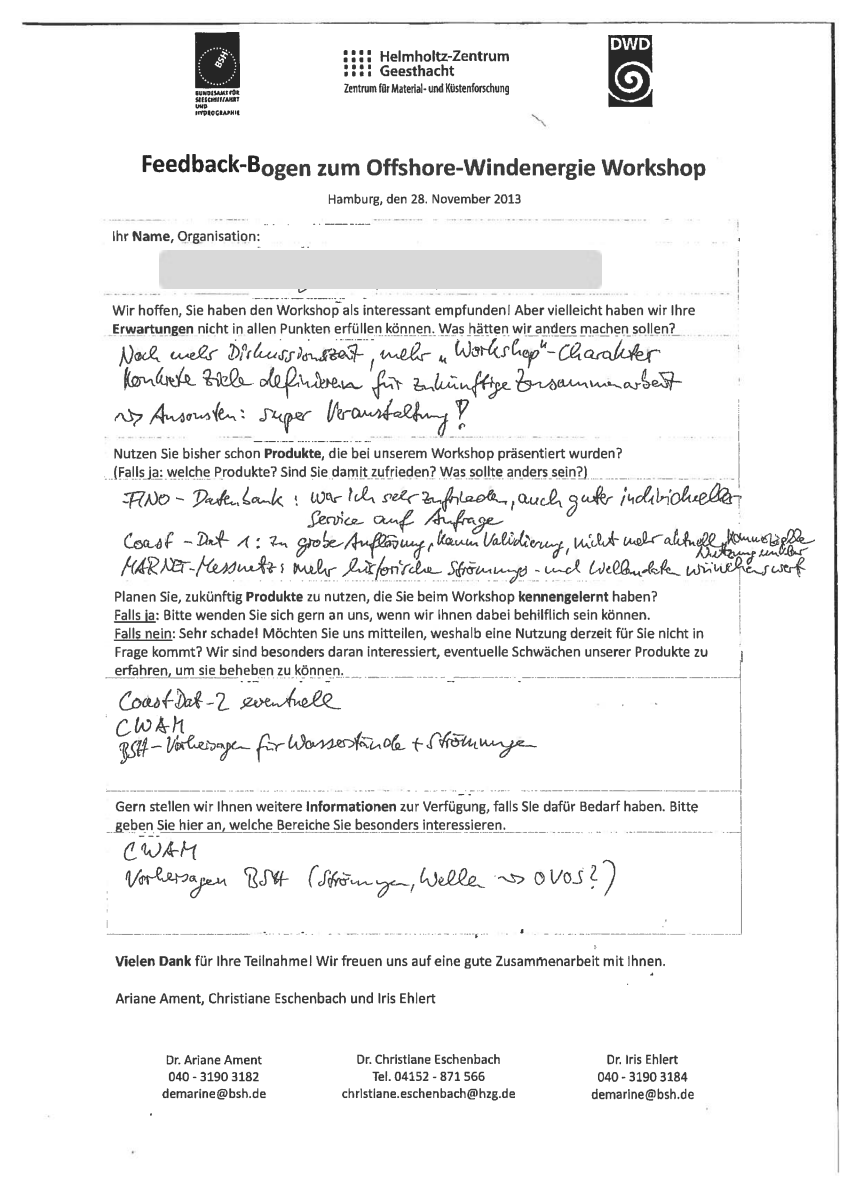

Figure 4. Feedback sheet as an example.

tent and complete data sets (without gaps) are essential. In addition, accurate and reliable data are particularly needed when weather and oceanographic conditions, such as wave heights, impede continuation of work. Under these circumstances, data quality is a liability issue.

User-friendly interfaces with elaborated filter functions would be helpful. Time slots with certain weather conditions should easily be identified; for example, a $6 \mathrm{~h}$ time slot with wave heights below $2.5 \mathrm{~m}$ might be necessary for certain maintenance operations. Several interviewees expressed a considerable willingness for co-operation concerning oceanographic measurements within wind farms and data exchange.

From the second series of interviews, after the first workshop and in preparation for the second workshop, a considerable demand for high-quality meteorological and oceanographic data and forecasts was confirmed. Data on current and wind fields are of special importance. The data should be provided 24 hours a day and 7 days a week (24/7) and with warranty. Some companies seriously considered exchanging their data for COSYNA and BSH data and allowing measurements within the wind farms.

\subsubsection{Workshops}

As we learned from the interviews that Environmental Protection, Health Management and Safety (EHS) plays a pivotal role, the safety aspect became an integral part of the first workshop entitled "New Products for Offshore Wind Energy Support. More Safety and Efficiency through Detailed Condition Assessment and Predictions". The program comprised the four sections introduction, risk assessment, state description, and forecasts, with each section covering the presentation of (scientific) data products, related user statements, and discussion. In total, 92 representatives from 33 different organizations participated: scientists, engineers, representatives of regulatory bodies, insurance companies, and offshore wind energy enterprises discussed questions concerning measurements and forecasts of currents, winds, and waves. The feedback on the workshop, gathered via feedback sheets (Fig. 4) was very positive. For example, most participants intended to use the data products presented at the workshops in future. It was suggested that the subsequent meetings should allow more time for discussion, resulting in "real" workshops. Thus, the second workshop was designed to be product-oriented and only a limited number of participants were invited to participate, ensuring a focus on discussions. The topical focus was on "Waves and Currents Measurements and Forecasts".

Follow-up meetings with representatives of individual enterprises promised collaboration and possibilities for undertaking measurements within a wind farm. Unfortunately, before becoming reality, the wind energy firms halted these collaborative endeavours due to internal constraints.

To summarize and rate the outcomes of the case study for COSYNA purposes, the most important finding was that COSYNA current and wave data and, in particular, forecasts would be the most welcome output. From the interviews and the workshops, we found that, for the offshore wind energy sector, the most interesting questions in COSYNA context are when do currents, waves, and winds enable safe construction and maintenance operations; can time slots with certain suitable weather and ocean conditions, i.e. wave height $<2.5 \mathrm{~m}$, be forecasted with sufficient accuracy; what are the sea and wave conditions along the shipping routes that will be regularly travelled to perform maintenance of realized or planned offshore wind farms; and can new technologies or observational concepts be deployed to protect wind turbines in case of sudden wind gusts. Safety of operations emerged as the overarching issue, meaning that reliability and completeness of data sets are indispensable - a requirement to be met by $24 / 7$ services. With respect to usability, a good user interface is essential, although the different specifications for "good" cannot easily be served by a single approach. In the context of collaboration, many enterprises would welcome data exchange and even joint measurements in wind farms were generally considered possible. Specific endeavours, however, were blocked. 


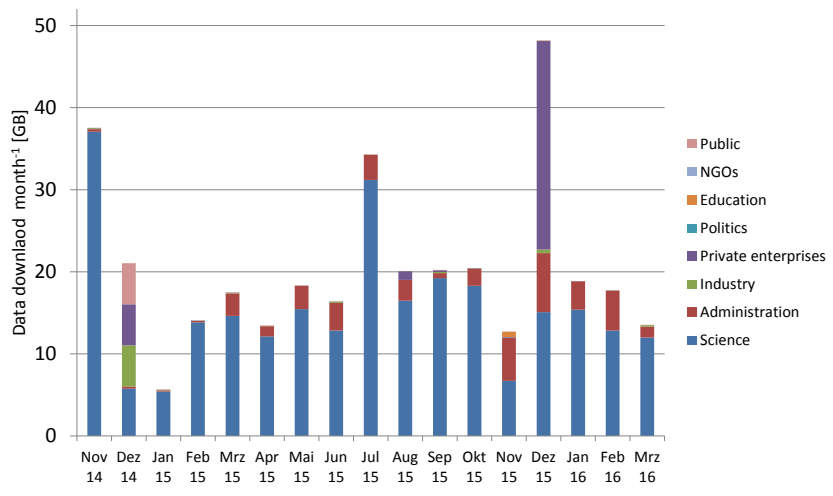

Figure 5. COSYNA data download sorted by user categories (November 2014 to March 2016; data provided by G. Breitbach).

\section{Impact evaluation (G)}

Finally, the question is how to measure the impact of data products for users or for society. In order to evaluate whether and when the COSYNA oceanographic products as well as the stakeholder interaction process were more or less successful, we used direct and indirect indicators. In order to assess the interaction process, direct feedback from involved stakeholders was gathered via evaluation and feedback sheets, during interviews and workshops. The unforeseen high participation numbers in the workshops also indicate a successful interaction process.

Concerning the products, the demands derived from the initial surveys and interviews are generally met by COSYNA observational and modelled data, which have attained a high scientific standard and provide a high degree of accuracy. Concerning data availability, (potential) users from the offshore wind energy sector referred to continuity and reliability as essential. COSYNA provides free public access to its data and metadata. As bound into the research context, it cannot, however, guarantee that data are available 24/7 without fail. The COSYNA Data Disclaimer states "no warranty is made, expressed, or implied, regarding the accuracy or validity of the data, or regarding the suitability of the data for any particular application".

We know from the recently introduced COSYNA data portal user registration that users from industry and private enterprises (small and medium enterprises, SME) account only for a small portion of the data download (Fig. 5). As COSYNA is committed to an open data policy and does not collect any personal user data, any information on users is limited to download rates and information provided voluntarily on user categories. On average, ca. 19 GB of COSYNA data were downloaded per month from November 2014 to March 2016. Users from the category of science downloaded the highest proportion of data, followed by users from "administration". During some months, however, other user groups used COSYNA data for specific purposes. In December 2015, for example, private enterprises used data to validate their model. Whether the greater diversity of data users in December 2014 is a direct result of the workshops cannot be validated.

\section{Discussion}

COSYNA represents scientific knowledge production in the field of coastal research; however, according to the societal demands, e.g. reflected by the mission of the Helmholtz Association (www.helmholtz.de/en/), it must also meet knowledge requests for solving societal problems. The type of topics addressed in COSYNA, i.e. coastal oceanographic research, is still new to transdisciplinary approaches. Thus, these studies are at the interface of transdisciplinary and coastal science research, and the COSYNA experiences can contribute new practical examples to both fields.

\subsection{The usability of the products}

The utility of products in large part is a question of the parameter, scale, accuracy, and availability fit. In order to gather the respective information on (potential) user demands and to improve the products accordingly, a dialogue with interest groups is indispensable. From the various surveys and stakeholder interactions it is clear that there is a considerable demand for meteorological and oceanographic data and forecasts, and COSYNA meets these requirements well. COSYNA products can support different interest groups from the offshore wind sector in overcoming the challenges related to ensuring safe, efficient, and effective maintenance and operation of the wind farms. On the other hand, from the case study, it can be concluded that COSYNA products in their recent form do not completely fit the specific demands of the offshore wind sector. These findings are in agreement with the fact that COSYNA products are mainly downloaded from the data portal by users from science, and to a lesser extent by those from administration and rarely from business enterprises.

As COSYNA products are developed in a research context, they cannot meet the whole palette of users' wishes and demands. For example, they cannot be provided 24/7 and with warranty (as, for example, required by the offshore wind energy sector). Certainly, asymmetries exist in perspective, functions, and agendas between scientists and business enterprises. The primary institutional commitment of scientists in traditional academia is to produce data that can be published and used for further research in the international scientific community, whereas enterprises seek economically sound solutions (see also Wiek, 2007).

The aim of a transdisciplinary approach is to open up traditional roles. User-oriented approaches became common, for example, in the field of climate research. The term "climate services" was used for the "generation, provision, and con- 
textualization of information and knowledge derived from climate research for decision-making at all levels of society" (Vaughan and Dessai, 2014). The concept of "products" and "services" is closely aligned, but there is a distinct difference: products are tangible (including digital) outputs, but a service produces an intangible benefit and satisfies an identified need. The roles in the science-society system should be considered in discussion of achievements and further desirable products and services. COSYNA develops data and data products and provides these products on a preoperational level to be of use for multiple interest groups in science, industry, agencies, politics, environmental protection, or the public. On the other hand, the national monitoring authorities, such as the BSH, provide services working in an operational mode (24/7). COSYNA research activities are regarded as improving these services; the COSYNA preoperational products can be taken over and utilized on an operational basis by the government agencies. Due to their "public status", neither COSYNA nor national monitoring authorities can offer concrete services for single enterprises in the offshore wind energy sector - or any other sector.

In accordance with the PDCA approach and the life cycle concept, the COSYNA products and their presentations are still undergoing improvement to attract more/further interest as well as to be more useful to (potential) users. For example, potential benefits can be assumed for resource management and sustainable development of the North Sea (according to MSFD).

\subsection{The stakeholder process - push or pull strategy?}

During the process studied here, a complete set of stakeholder interactions was applied, ranging from initial situational analysis through external evaluation, interviews, and workshops with potential users, to meetings focused on data exchange and joint measurements. Through the various interactions with different stakeholders the COSYNA products could be improved substantially. In addition, especially the interaction with the key stakeholders from the offshore energy sector led to essential insights into the demands and constraints concerning the use and usability of COSYNA products, and identified new research questions. Although the most challenging steps of co-operation or collaboration could not be achieved, the entire process of stakeholder interaction should be considered successful.

Different interaction intensities, such as "information", "consultation", and "co-operation" are possible between science and stakeholders (Brinkmann et al., 2015; Stauffacher et al., 2008; Wiek, 2007). One-way information from COSYNA to the stakeholders was provided via traditional media, such as brochures, flyers, website, attendance, booths at exhibitions, and presentations during workshops. The "consultation" encompasses one-way communication through questionnaires/surveys and was specifically addressed through face-to-face interviews. Requirements for content and presentation of data products from the offshore side and the capabilities of the coastal science side were successfully worked out. The subsequent steps, "co-operation" and "collaboration", focus on exchange. In one case, decisions are made by the scientific partner and in the other, both partners collaborate equally. Co-operation or collaboration was the aim in follow-up meetings, concretely focusing on data exchange between COSYNA and offshore wind enterprises and on joint measuring activities within wind farms. Internal constraints of the offshore wind energy sector, however, prevented the interaction process from being truly collaborative.

Revisiting the ideal assessment design of stakeholder interaction outlined above, we acknowledge that this ideal was not fully achieved for the COSYNA products. This is partly due to limited resources, but also to the fact that the products developed by a research institute cannot always be tailored to the specific demands of every individual user. It would have been useful to include a larger number of different stakeholders in the later stages of the process, however, this was not possible due to resource constraints.

COSYNA experiences underpin the fact that long-term contacts are necessary to allow for intensification of stakeholder involvement and to enable co-operation or collaboration. Stakeholder interaction has so far applied more or less a "push" strategy, where the idea is to promote products by pushing them toward people. In order to adopt the idea of pull marketing (to establish a loyal following and draw consumers to the products), long-term contacts with stakeholders and potential users of science products need to be established.

\subsection{Contribution to impact evaluation - "the product has to be attractive for the stakeholder, not only for the scientist"}

COSYNA has articulated high expectations for scientific and societal impact. A major question still remains: how can the impact be assessed and what might be the possible criteria for success.

Certainly, assessment of success strictly depends on what is considered successful as a scientific research undertaking. The criteria are, or seem to be, clear as long as only the closed system of traditional academia is taken into consideration; the main or single criterion is the number of peerreviewed scientific articles in international English-speaking journals (see also Wiek, 2007). In addition, the perception of what would constitute success of a research project does not only vary between scientists and stakeholders, but also may considerably differ between scientific peers (e.g. Allen et al., 2013). However, the scope of impact evaluation of research has become wider and the societal impact of research is an increasingly important factor (e.g. Godin and Doré, 2007; Bornmann, 2012, 2013). For transdisciplinary approaches, the relationship between different collaborative 
methods, processes, or concepts and the desired effects are less clear. Quality standards and evaluation criteria are a matter of research and discussion in the respective scientific communities (e.g. Bergmann et al., 2016). Experiences from projects are considered to contribute to their development and establishment. In COSYNA, data download values are used to indicate application of data (for example for model validation, December 2015). The level of awareness (indicated by number of visits to the website) and the rate of data download can be considered preconditions for usage and societal impact of COSYNA data products. Whether or not the data downloaded are really used and helpful in supporting decision-making cannot be assessed in this study. It is, however, the subject of ongoing research and discussion.

In the context of COSYNA and partner and predecessor projects, a number of initiatives can be identified, where success and impact of oceanographic science research efforts can be demonstrated. The one thing that all these successful initiatives have in common is that stakeholders were integrated from the beginning of the project. Some examples include

- Technological developments, such as new (automated) sensors or underwater node technologies, have been handed over to other institutions for regular measurements (Marine Environmental Remote-controlled Measuring and Integrated Detection, MERMAID; Contaminants and Nutrients in Variable Sea Areas, CANVAS).

- In order to improve their regular monitoring, national authorities have adopted observation strategies that are based on a scientifically improved understanding of the ecosystems (MERMAID, CANVAS; Knauth et al., 1997; Nies et al., 1999).

- Calibration and maintenance procedures have been harmonized within the framework of a joint EU project and are now used by a broad range of European institutions (JERICO, http://www.jerico-fp7.eu/; Petihakis et al., 2015).

- Co-operation exists with operational agencies to improve ocean wave forecasting services (e.g. Behrens, 2015).

- With the model-based database coastDat, many aspects of marine climate (storms, waves, surges, etc.) over many decades are reconstructed. The data set is used by more than 80 users with about $47 \%$ of them located in industry, $15 \%$ in government bodies, and $38 \%$ in other research institutes (www.coastdat.de/; Weisse et al., 2008, 2015).

- Data management methods developed in COSYNA are a relevant part of a larger networked coherent data portal (MaNIDA, www.manida.org/)
From these examples taken from oceanographic research, the following criteria for success and (societal) impact of products or services can be derived. (1) Awareness of the necessity for system understanding is being increased. (2) Observational approaches, (3) technological developments, (4) modelling components, or (5) data products have been taken over by national authorities, business enterprises, or other research institutions.

Experiences from this study can contribute to identifying a structured process for integrating transdisciplinary approaches into coastal oceanographic research and for further developing evaluation criteria for the multi-attributive assessments needed in such "non-linear" science endeavours.

Acknowledgements. This work has been supported through the Coastal Observing System for Northern and Arctic Seas (COSYNA). The author acknowledges input and help from numerous colleagues contributing to COSYNA, on which this study is based. I owe special thanks to Ariane Ament for pleasant and fruitful teamwork while organizing offshore wind park interviews and workshops. Gisbert Breitbach provided the data usage statistics for the COSYNA data portal downloads. Friedhelm Schroeder and Holger Brix provided comments that helped improve earlier drafts of the manuscript.

The article processing charges for this open-access publication were covered by a Research Centre of the Helmholtz Association.

Edited by: O. Zielinski

Reviewed by: two anonymous referees

\section{References}

Ahrendt, K. and Wesnigk, J. B.: Studie über das mögliche Potential des COSYNA-Systems - Befragung und Analyse vier nationaler Interessensgruppen, HZG internal report, 39 pp., 2009.

Allen, E., Kruger C., Leung, F.-Y., and Stephens, J. C.: Diverse Perceptions of Stakeholder Engagement within an Environmental Modeling Research Team, J. Environ. Stud. Sci., 3, 343-356, doi:10.1007/s13412-013-0136-x, 2013.

Bailey, H., Brookes, K. L., and Thompson P. M.: Assessing environmental impacts of offshore wind farms: lessons learned and recommendations for the future, Aquatic Biosystems, 10, 1-13, 2014.

Baschek, B., Schroeder, F., Brix, H., Riethmüller, R., Badewien, T. H., Breitbach, G., Brügge, B., Colijn, F., Doerffer, R., Eschenbach, C., Friedrich, J., Fischer, P., Garthe, S., Horstmann, J., Krasemann, H., Metfies, K., Ohle, N., Petersen, W., Pröfrock, D., Röttgers, R., Schlüter, M., Schulz, J., Schulz-Stellenfleth, J., Stanev, E., Winter, C., Wirtz, K., Wollschläger, J., Zielinski, O., and Ziemer, F.: The Coastal Observing System for Northern and Arctic Seas (COSYNA), Ocean Sci. Discuss., doi:10.5194/os2016-31, in review, 2016.

Behrens, A.: Development of an ensemble prediction system for ocean surface waves in a coastal area, Ocean Dynam., 65, 469486, 2015. 
Bergmann, M., Jahn, T., Lux, A., Nagy, E., and Schäfer, M.: Transdisciplinary Research that becomes Effective. TransImpact Analyses Transdisciplinary Projects, GAIA 25/1, 59-60, 2016.

Bernstein, J. H.: Transdisciplinarity: A review of its origins, development, and current issues, Journal of Research Practice, 11, Article R1, available at: http://jrp.icaap.org/index.php/jrp/article/ view/510/412 (last access: 3 November 2016), 2015.

Bornmann, L.: Measuring the societal impact of research, EMBO Reports, 13, 673-676, 2012.

Bornmann, L.: What Is Societal Impact of Research and How Can It Be Assessed? A Literature Survey, J. Am. Soc. Inform. Sci. 64, 217-233, 2013.

Bowyer, P., Brasseur, G., and Jacob D.: The Role of Climate Services in Adapting to Climate Variability and Change 533-550, in: Handbook of Climate Change Adaption, edited by: Leal Filho, W., Springer, Berlin, Heidelberg, doi:10.1007/978-3-642-386701_29, 2015.

Breitbach, G., Krasemann, H., Behr, D., Beringer, S., Lange, U., Vo, N., and Schroeder, F.: Accessing diverse data comprehensively - CODM, the COSYNA data portal, Ocean Sci., 12, 909-923, doi:10.5194/os-12-909-2016, 2016.

Brinkmann, C., Bergmann, M., Huang-Lachmann, J., Rödder, S., and Schuck-Zöller, S.: Zur Integration von Wissenschaft und Praxis als Forschungsmodus - Ein Literaturüberblick, Report 23, Climate Service Center Germany, Hamburg, 76 pp., 2015.

Buskey, E. J., Bundy, M., Ferner, M.C., Porter, D. E., Reay, W. G., Smith, E., and Trueblood, D.: System-Wide Monitoring Program of the National Estuarine Research Reserve System: Research and Monitoring to Address Coastal Management Issues, in: Coastal Ocean Observing Systems, edited by: Liu, Y., Kerkering, H., and Weisberg, R. H., Elsevier Inc., 392-415, doi:10.1016/B978-0-12-802022-7.00021-3, 2015.

Cash, D. W., Clark, W. C., Alcock, F., Dickson, N. M., Eckley, N., Guston, D. H., Jäger, J., and Mitchell, R. B.: Knowledge systems for sustainable development, P. Natl. Aacad. Sci. USA, 100, 8086-8091, doi:10.1073_pnas.1231332100, 2003.

Clark, S., Schroeder, F., and Baschek, B.: The influence of large offshore wind farms on the North Sea and Baltic Sea - a comprehensive literature review, HZG Report 2014-6, 35 pp., 2014.

Commission of the European Communities: Communication from the Commission to the European Council and the European Parliament: An Energy Policy for Europe, Brussels, 10.1.2007, COM(2007) 1 final, 2007.

DeLorme, D. E., Kidwell, D., Hagen, S. C., and Stephens, S. H.: Developing and managing transdisciplinary and transformative research on the coastal dynamics of sea level rise: Experiences and lessons learned, Earth's Future, 4, 194-209, doi:10.1002/2015EF000346, 2016.

Deutscher Bundestag: Federal Law Gazette (Bundesgesetzblatt): Renewable Energy Sources Act (Gesetz für den Vorrang Erneuerbarer Energien (Erneuerbare-Energien-Gesetz - EEG) sowie zur Änderung des Energiewirtschaftsgesetzes und des Mineralölsteuergesetzes), 2000, I, 13, 305-309, www.gesmat.bundesgerichtshof.de/gesetzesmaterialien/15_ wp/ErnEnerg_KWK_14_Wp/bgbl100s0305.pdf (last access: 3 November 2016), 2000.

Diedrich, A., Tintore, J., and Navines, F.: Balancing science and society through establishing indicators for integrated coastal zone management in the Balearic Islands, Mar. Policy., 34, 772-781, doi:10.1016/j.marpol.2010.01.017, 2010.

Directive 2008/56/EC: European Parliament and of the Council of 17 June 2008 establishing a framework for community action in the field of marine environmental policy (Marine Strategy Framework Directive), OJ L 164, 25 June 2008, 19-40, doi:10.1175/WCAS-D-11-00034.1, 2008.

Eschenbach, C.: Coastal Observing System for Northern and Arctic Seas: User interactions in COSYNA, Loicz inprint 2012/3, 9-16, 2013.

Fischer, J. and Flemming, N. C.: Operational Oceanography: Data Requirements Survey, EuroGOOS, Publication No. 12, Southampton Oceanography Centre, Southampton, 1999.

Godin, B and Doré, C.: Measuring the Impacts of Science: Beyond the Economic Dimension, Paper presented at the Helsinki Institute for Science and Technology Studies, HIST Lecture, $24 \mathrm{Au}-$ gust 2007, Helsinki, Finland, 2007.

Hirsch Hadorn, G., Hoffmann-Riem, H., Biber-Klemm, S., Grossenbacher-Mansuy, W., Joye, D., Pohl, C., Wiesmann, U., and Zemp, E. (Eds.): Handbook of Transdisciplinary Research, Springer, Netherlands, 448 pp., doi:10.1007/978-1-4020-6699-3, 2008.

Hoffmann-Riem, H., Biber-Klemm, S., Grossenbacher-Mansuy, W., Hirsch Hadorn, G., Joye, D., Pohl, C., Wiesmann, U., and Zemp, E.: Idea of the handbook. In: Hirsch Hadorn, G., Hoffmann-Riem, H., Biber-Klemm, S., Grossenbacher-Mansuy, W., Joye, D., Pohl, C., Wiesmann, U., and Zemp, E. (Eds.): Handbook of Transdisciplinary Research, Springer, Netherlands, 3-18, doi:10.1007/978-1-4020-6699-3, 2008.

Jahn, T., Bergmann, M., and Keil, F.: Transdisciplinarity: Between mainstreaming and marginalization, Ecol. Econ., 79, 1-10, doi:10.1016/j.ecolecon.2012.04.017, 2012.

Knauth, H.-D., Schroeder, F., Menzel, R., Gebhart, E., Marx, S., Kohnke, D., Holzkamm, F., Nies, H., and Theobald, N.: Marine pollution network euromar-mermaid: Results of the experimental operation, Deutsche Hydrografische Zeitschrift, September 1997, 49, 385-407, 1997.

Kourafalou, V. H., De Mey, P., Staneva, J., Ayoub, N., Barth, A., Chao, Y., Cirano, M., Fiechter, J., Herzfeld, M., Kurapov, A., Moore, A. M., Oddo, P., Pullen, J., Van Der Westhuysen, A., and Weisberg, R. H.: Coastal Ocean Forecasting: science foundation and user benefits, Journal of Operational Oceanography, 8, 147 167, doi:10.1080/1755876X.2015.1022348, 2015a.

Kourafalou, V. H., De Mey, P., Le Hénaff, M., Charria, G., Edwards, C. A., He, R., Herzfeld, M., Pascual, A., Stanev, E. V., Tintoré, J., Usui, N., van der Westhuysen, A. J., Wilkin, J., and Zhu, X.: Coastal Ocean Forecasting: system integration and evaluation, Journal of Operational Oceanography, 8, 127-146, doi:10.1080/1755876X.2015.1022336, 2015b.

Kvale, S.: Ten Standard Objections to Qualitative Research Interviews, J, Phenomenol. Psychol., 25, 147-173, 1994.

Laane, R. W. P. M.: COSYNA: Coastal Observation System for Northern and Arctic Seas - Feasibility study on the international dimension of COSYNA, HZG internal Report, 30 pp., 2010.

Liu, Y., Kerkering, H., and Weisberg, R. H. (Eds.): Coastal Ocean Observing Systems, Academic Press, 490 pp., doi:10.1016/B978-0-12-802022-7.00022-5, 2015. 
Mackinson S., Wilson D. C., Galiay P., and Deas B.: Engaging stakeholders in fisheries and marine research, Mar. Policy, 35, 18-24, doi:10.1016/j.marpol.2010.07.003, 2010.

McNie, E. C.: Delivering Climate Services: Organizational Strategies and Approaches for Producing Useful Climate-Science Information, Weather Climate Soc., 5, 14-26, 2013.

Nies, H., Brugge, B., Sterzenbach, D., Knauth, H.-D., and Schroeder, F.: Contaminants and Nutrients in Variable Sea Areas (CANVAS) - Application of Automatic Monitoring stations in the German Marine Environment, IAEA Tec-Doc 1094 IAEASM-354/97P, Marine Pollution: Proceedings of a symposium held in Monaco, 5-9 October 1998, 414-415, 1999.

Petihakis, G., Petersen, W., Nair, R., Faimali, M., Pavanello,G., Boukerma, K., Delauney, L., Puillat, I., Farcy, P., and Greenwood, N.: Harmonization in the joint European research infrastructure network for coastal observatories - JERICO, IEEE Conference Publications, OCEANS 2015 - MTS/IEEE, Washington, $1-8,2015$.

Pettibone, L. and Lux A.: GEWISS Dialogforum: Webinare zu Citizen Science jenseits der Naturwissenschaften, GEWISS Bericht Nr. 5. Berlin, 2015.

Pineda, I. (Ed): The European offshore wind industry - key trends and statistics 1st half 2015. Report, European Wind Energy Association, 9 pp., 2015.

Porter, D. E., Dorton, J., Leonard, L., Kelsey, H., Ramage, D., Cothran, J., Jones, A., Galvarino, C., Subramanian, V., and Hernandez, D.: Integrating Environmental Monitoring and Observing Systems in Support of Science to Inform Decision-Making: Case Studies for the Southeast, in: Coastal Ocean Observing Systems, edited by: Liu, Y., Kerkering, H., and Weisberg, R. H., Elsevier Inc., 416-429, doi:10.1016/B978-0-12-802022-7.000225, 2015.

Rebitzer, G., Ekvall, T., Frischknecht, R., Hunkeler, D., Norris, G., Rydberg, T., Schmidt, W.-P., Suh, S., Weidema, B.P., and Pennington, D. W.: Life cycle assessment Part 1: Framework, goal and scope definition, inventory analysis, and applications, Environ. Int., 30, 701-720, 2004.

Schulz-Stellenfleth, J., Wahle, K., Stanev, A. J., Seemann, J., Cyseswki, M., Gurgel, K. W., Schlick, T., Ziemer, F., and Stanev, E.: Nutzung eines HF-Radarsystems zur Beobachtung und Vorhersage von Strömungen in der Deutschen Bucht im Rahmen von COSYNA, DGM, 10/3, 3-8, 2010.

Simoniello, C., Watson, S., Kirkpatrick, B., Spranger M., Jochens, A. E., Kobara, S., and Howard, M. K.: One system, many societal benefits: building an efficient, cost-effective ocean observing system for the Gulf of Mexico, in: Coastal Ocean Observing Systems, edited by: Liu, Y., Kerkering, H., and Weisberg, R. H., Elsevier Inc., 430-451, doi:10.1016/B978-0-12-8020227.00022-5, 2015.
Stanev, E. V., Schulz-Stellenfleth, J., Staneva, J., Grayek, S., Seemann, J., and Petersen, W.: Coastal observing and forecasting system for the German Bight - estimates of hydrophysical states, Ocean Sci., 7, 569-583, doi:10.5194/os-7-569-2011, 2011.

Stanev, E., Ziemer, F., Schulz-Stellenfleth, J., Seemann, J., Staneva, J., and Gurgel, K.-W.: Blending surface currents from HF radar observations and numerical modelling: Tidal hindcasts and forecasts, J. Atmos. Ocean. Technol., 32, 256-281, 2015.

Stauffacher, M., Flüeler, T., Krütli, P., and Scholz R. W.: Analytic and dynamic approach to collaboration, A Transdisciplinary Case Study on Sustainable Landscape Development in a Swiss Prealpine Region, in: Systemic Practice and Action Research, 21, 409-422, doi:10.1007/s11213-008-9107-7, 2008.

Thiel, M., Angel Penna-Díaz, M., Luna-Jorquera, G., Salas, S., Sellanes J., and Stotz W.: Citizen Scientists and Marine Research: Volunteer Participants, Their Contributions, and Projection for the Future, Oceanogr. Mar. Biol., 52, 257-314, 2014.

Vaughan, C. and Dessai, S.: Climate services for society: origins, institutional arrangements, and design elements for an evaluation framework, WIREs Clim Change, 5, 587-603, doi:10.1002/wcc.290, 2014.

von Storch, H. von, Emeis, K., Meinke, I., Kannen, A., Matthias, V., Ratter, B. M. W., Stanev, E., Weisse, R., and Wirtz, K.: Making coastal research useful- cases from practice, Oceanologia, 57, 3 16,2015

Weisse, R., Storch, H. V., Callies, U., Chrastansky, A., Feser, F., Grabemann, I., Guenther, H., Pluess, A., Stoye, T., Tellkamp, J., Winterfeldt, J., and Woth, K.: Regional meteo-marine reanalyses and climate change projections: Results for Northern Europe and potentials for coastal and offshore applications, B. Am. Meteorol. Soc. 90, 849-860, doi:10.1175/2008BAMS2713.1, 2008

Weisse, R., Bisling, P., Gaslikova, L., Geyer, B., Groll, N., Hortamani, M., Matthias, V., Maneke, M., Meinke, I., Meyer, E. M. I., Schwichtenberg, F., Stempinski, F., Wiese, F., and Wöckner-Kluwe, K.: Climate services for marine applications in Europe, Earth Perspectives, Transdisciplinarity Enabled, 2, doi:10.1186/s40322-015-0029-0, 2015.

Welp, M., de la Vega-Leinert, A., Stoll-Kleemann, S., and Jaeger, C. C.: Science-based stakeholder dialogues: Theories and tools, Global Environ. Change, 16, 170-181, 2006.

Wiek, A.: Challenges of Transdisciplinary Research as Interactive Knowledge Generation - Experiences from Transdisciplinary Case Study Research, GAIA 16, 52-57, 2007. 